\section{LA ILUSTRACIÓN GRÁFICA, COMPLEMENTO DOCUMENTAL EN LA ACTIVIDAD DEL URÓLOGO*}

\section{J.J. Ballesteros Sampol \\ Servicio de Urología. Hospital Nuestra Señora de la Esperanza. Barcelona.}

*En agradecimiento a J. García Crespo por sus enseñanzas.
$\mathrm{E}$ 1 grafismo acompaña a la actividad humana desde la prehistoria, de forma documentada, y se ha manifestado con múltiples y diferentes significados desde hace más de 25.000 años.

El mundo de hoy no puede prescindir de las imágenes en ninguna de sus actividades y relaciones dependiendo, muchas veces, del acierto en la elección de las mismas, el éxito de una campaña de solidaridad, comercial o política.

Obviando la ilustración como fin en si misma de todos los profesionales que viven de ella, no cabe duda que, también quienes no tenemos esta dependencia, podemos ver complementada nuestra actividad profesional con el recurso a tal ayuda.

$\mathrm{El}$ aforismo "Vale más una imagen que mil palabras" expresa, con matizaciones, la rapidez e instantaneidad con que nuestra mente capta todo el mensaje de una imagen que podría necesitar una exposición oral más prolija si careciéramos de la captación visual. Esa "muda elocuencia" era especialmente apreciada por un genio de la táctica militar como Napoleón para quien: "...un croquis vaut mieux qu'un long discours..."

La utilidad de este mdio complementario, ¿exige una especial habilidad artística?... Creo sinceramente que no o, por lo menos, no superior a la necesaria para realizar una pielo o uretroplastia. La finalidad de la ilustración propia, aún simple o esquemática, es la de representar una imagen partiendo de un modelo real o virtual al que aportamos una elaboración intelectual que pretende subrayar, destacar o realzar detalles de importancia para el adecuado conocimiento diagnóstico o la exposición de un método operatorio. La mejor o peor calidad de la ilustración repercutirá sólo en el hecho de que el esquema sea útil sólo para el que lo ha creado o sirva, además, para cualquiera que consulte el documento.

Durante mi época de estudiante en la Facultad de Medicina de Barcelona tuve la oportunidad de conocer y recibir enseñanzas de

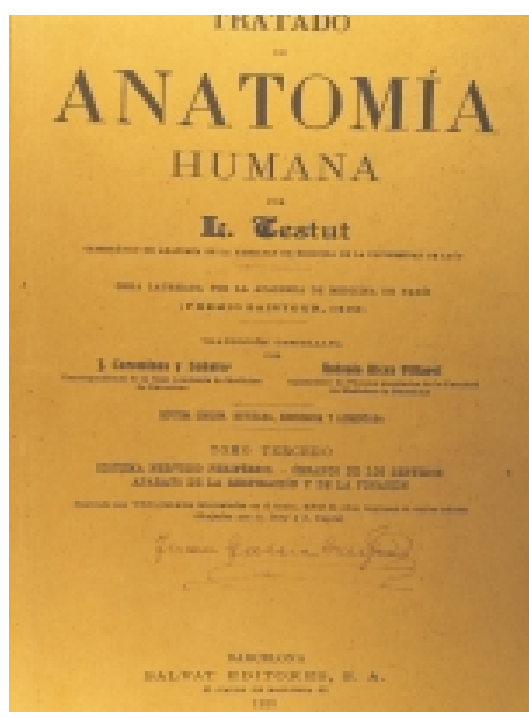

FIGURA 1. Portada de Anatomia Descriptiva. Testut edición de 1925. diversos docentes con distinta dotación para el dibujo o el esquema didáctico. Recuerdo perfectamente la habilidad del Dr. Lluch en Anatomía I reproduciendo en la pizarra, de forma excelente, los dibujos con que G. Devy, S. Dupret y E. Boulenaz iluminaban la mejor Anatomía que se ha escrito: "El Testut" (Fig. 1). Otro excelente dibujante fue el Profesor Azoy, cátedro de Otorrino, quien tenía la rara habilidad de ser ambidextro, lo que le daba una seguridad pasmosa para reproducir especialmente aquellos huesos como el etmoides o esfenoides que eran impares y medios. También el 


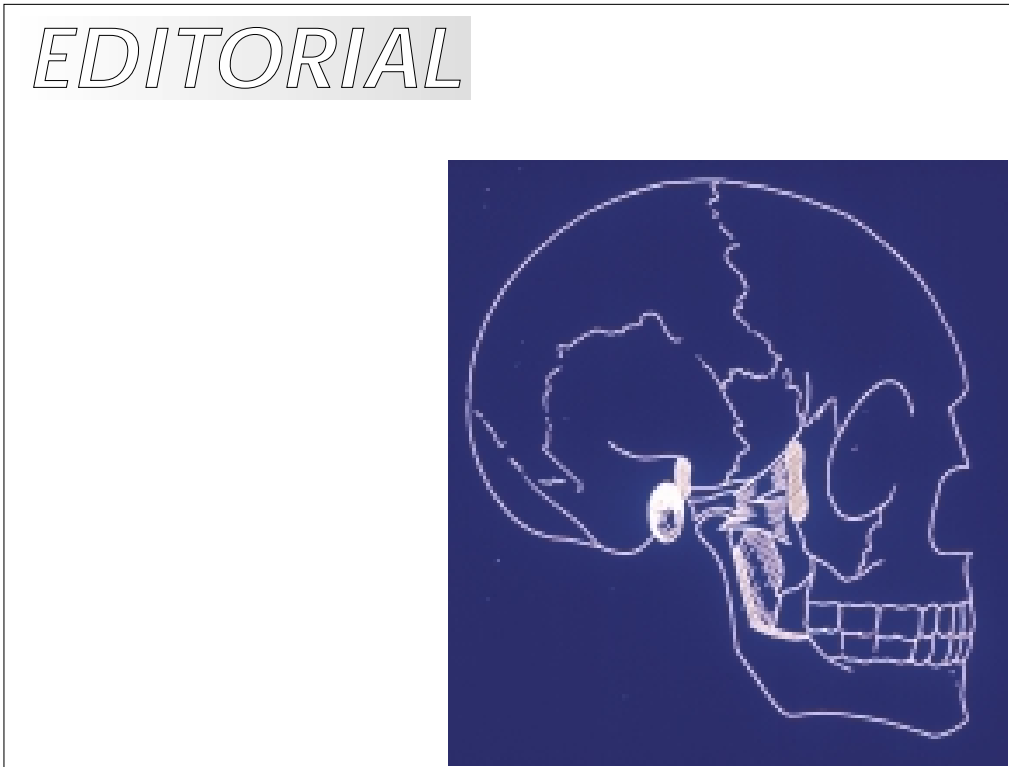

FIGURA 1bis: Dibujo realizado por el Prof. Ruano Gil para una clase de Anatomía.
Profesor Ruano Gil, cátedro de Anatomía, realiza sus propias ilustraciones para su actividad docente (Fig. 1 bis). No cabe duda de que, en tal aspecto, el apoyo de unos buenos dibujos contribuían a percibir la, para muchos "árida" asignatura, como mucho más atractiva.

Fuera del Centro Docente tuve la suerte de recibir las enseñanzas de un verdadero "maestro" en Anatomía: el Dr. García Crespo, traumatólogo con una gran vocación para la enseñanza y por transmitir la pasión que sentía por esa materia. Él me enseñó a estudiar siempre con una hoja al lado del libro y un bolígrafo en la mano. Cualquier tema era posible reflejarlo en un esquema, dibujo o algoritmo que facilitara su rápida comprensión y aprehensión. Su influencia ha sido tan perdurable que aún hoy tengo ese hábito la mayoría de veces que pongo delante de mí un texto, artículo, etc.

Ya médico, durante mi formación en la Escuela Profesional de Urología de José María Gil Vernet, mi afición por el dibujo hizo que tuviera que hacer muchos esbozos de técnicas quirúrgicas del, entonces, mi maestro. Lo recuerdo con cariño y nostalgia aunque no se me olvidan las veces que, al presentarle unos dibujos ya bastante definitivos, cogía un lápiz rojo o un bolígrafo y me los "deshacía" literalmente por no haber sabido captar su idea ...y vuelta a empezar!

Como decía antes, no es necesario ser buen dibujante para ejercitar estos métodos auxiliares. Muchas veces son esquemas para los que sólo se necesita trazar líneas, rectas, quebradas u oblicuas. El catedrático que tuve en Patologías Médicas, Don Máximo Soriano Giménez tuvo el acierto de presentar, cada día durante los tres cursos que duraba entonces la asignatura, un enfermo de la sala para ser historiado y explorado por dos de nosotros... Uno se dedicaba al interrogatorio siguiendo la "pista" de los famosos "signos guía" que nos enseñó a detectar para, a partir de ellos, avanzar en la obtención del diagnóstico. Tales signos eran señalizados por el compañero en la pizarra sobre tres líneas maestras que reflejaban "el síndrome febril", "el síndrome tóxico" y "el síndrome local" (Fig. 2). La historia clínica, pues, quedaba grabada en tres ejes sobre los que se dibujan las agujas

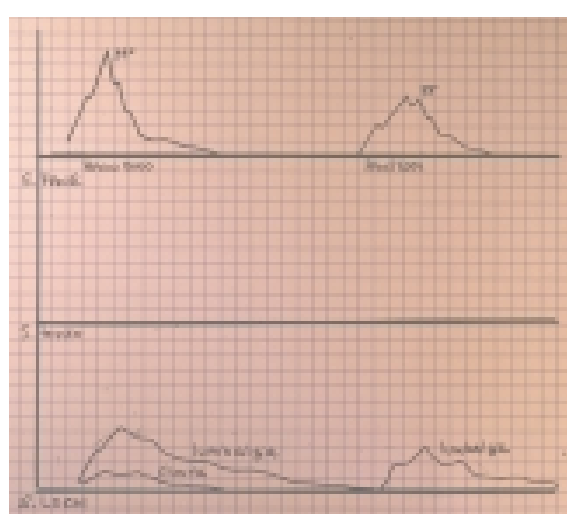

FIGURA 2. Esquema gráfico de historia clinica (Apuntes de la Cátedra de Patología Médica. Prof. Máximo Soriano). 
correspondientes a los hallazgos clínicos significativos y era perfectamente posible describir una enfermedad que había ocasionado un síndrome febril de " $x$ " características gráficas acompañado de una inapetencia, astenia o pérdida de peso y acompañado de un dolor lumbar sordo, por ejemplo...y que, tal vez, se había repetido una o dos veces en los últimos 2 años... Y todo eso sólo con unas sencillas gráficas.

Lógicamente en aquellos años era mucho mayor la dependencia de esos medios auxiliares de lo que es ahora. Lo que hacían los internos de Anatomía II del Prof. Salvador Gil Vernet (Fig. 3) pasando a tinta china de colores las preparaciones histológicas de los cortes histopográficos de más de 3.000 bloques de pelvis humanas fue una labor monumental, hoy desgraciadamente muy dispersa cuando no hurtada. Todo ese ingente material junto con las preparaciones histológicas no ha podido ser recogido por nadie que siguiera la fecunda línea investigadora de Don Salvador en este campo de la anatomía pelviana masculina. Me ha parecido inexcusable rendir un tributo de agradecimiento a esos "internos" reproduciendo uno de tales cortes firmado por "el alumno F. Rodríguez Méndez" (Fig. 4), hoy anatomopatólogo en ejercicio.

El urólogo de hoy puede repartir o dedicar su actividad profesional entre la asistencia, la enseñanza o la búsqueda e investigación, publicamos artículos de la especialidad, dictamos conferencias o participamos en reuniones, damos clases en pregrado, formamos postgrados, etc. Un amplio abanico de opciones en las que la ilustración puede sernos de gran utilidad.

El documento básico asistencial, nadie lo duda, es la Historia Clínica. Ya he comentado como tuve la suerte de tener a un gran maestro del que no hemos olvidado como realizarla. Además, en Urología, el diagnóstico se basa esencialmente en el apoyo de las técnicas de imagen (UIV, Ecografía, TAC, RNM, Divas, etc...). Para mi ha sido siempre muy importante "añadir" en las hojas de

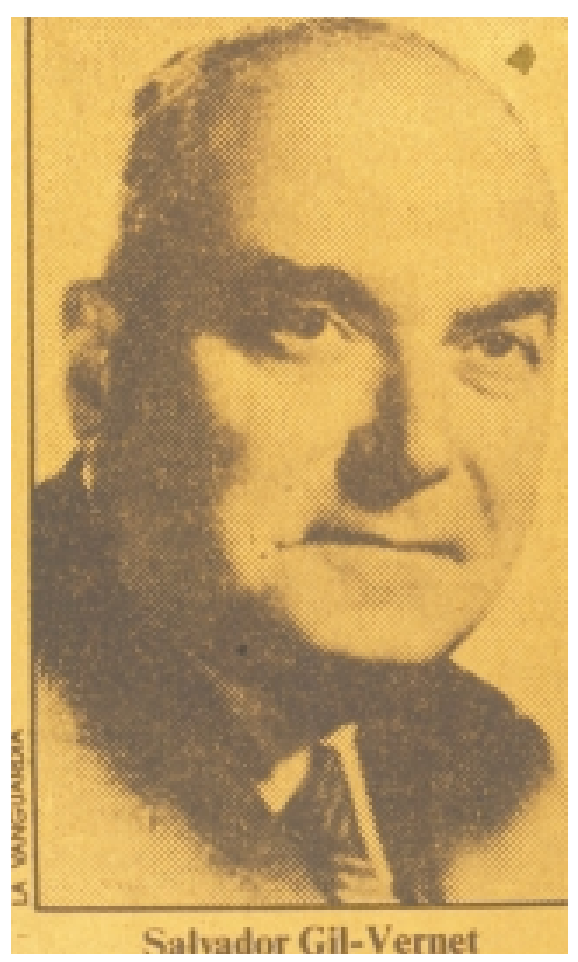

FIGURA 3. Salvador Gil-Vernet, cátedro de Anatomía II de la Facultad de Medicina de Barcelona.

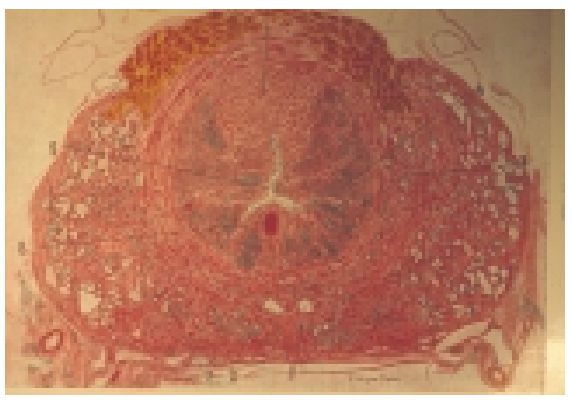

FIGURA 4. Corte histotopográfico de la glándula prostática realizado a la plumilla con tinta china coloreada por el alumno $F$. Rodriguez Méndez (1958?). 
la Historia la reproducción de una urografía, arteriografía o TAC, características (Figs. 5 y 6) en las que, intencionadamente se subrrayaban, realzaban o exageraban los detalles más interesantes o de utilidad en la posterior actuación quirúrgica. Es cierto que uno puede volver a ver, siempre que lo desee, aquellas placas hechas con anterioridad al momento actual pero no es menos cierto, también, que en historias voluminosas puede no ser nada sencilla esta búsqueda $\mathrm{y}$, alguna que otra vez, pueden resultar extraviadas partes de tales exploraciones. Además, la inmediatez especial de tener junto al comentario clínico la imagen realzada en lo más interesante, a mí, siempre me ha sido muy útil.

Para los cirujanos, la Hoja Operatoria es otro gran documento que, además, puede ser la mejor defensa del médico en asuntos legales. En mi Servicio siempre se ha dado mucha importancia a la relación escrita de los sucesos acaecidos en las intervenciones. Además del ejemplar que se adjunta a la Historia Clínica, tenemos una copia confeccionando el llamado "Libro de Quirófano" (idea inculcada por Pablo Carretero cuando, en 1967 llegó de Alemania al HCP de Barcelona). Dichas "Hojas" están todas ellas escritas a máquina (ahora ordenador) para que no haya dudas en la interpretación del texto $\mathrm{y}$, muchas de ellas se acompañan del esquema o dibujo operatorio (Figs. 7 y 8). Además del valor documental tiene otro añadido, docente, ya que sirve como "texto de técnicas quirúrgicas" para los miembros del Servicio que

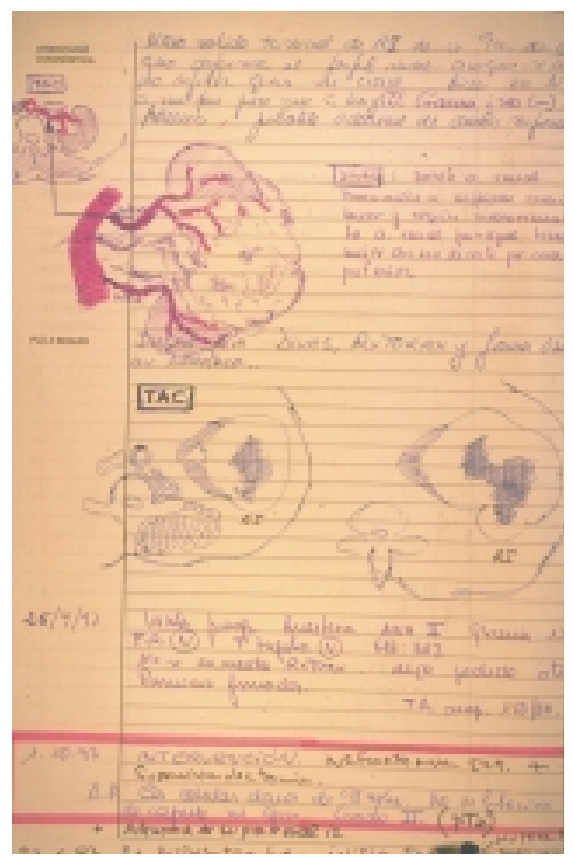

FIGURA 5. Ilustración personal en historia clinica de una arterio y TAC de tumor renal.

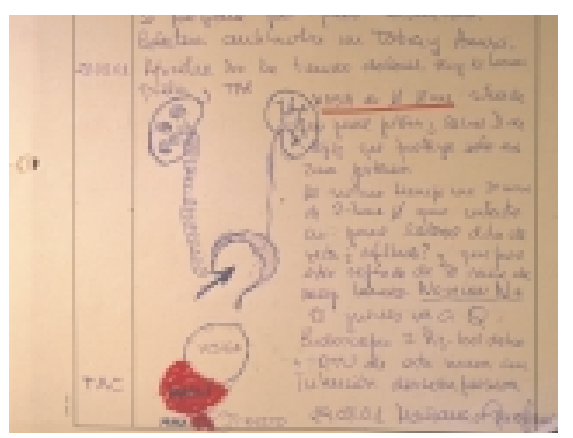

FIGURA 6. Idem. De una recidiva local a 8 años de una prostatectomía radical.

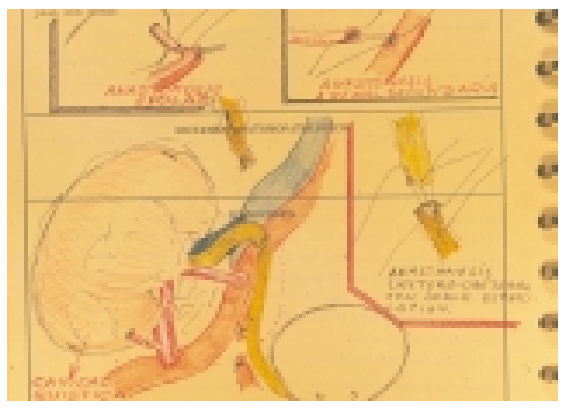

FIGURA 7. Idem. En Hoja Operatoria de un trasplante renal con anomalias vasculares. se hallen en periodo formativo.

Se podría argüir que una imagen puede ser más real si se refleja en una fotografía o "slide" pero la homogenización de la coloración rojiza de 


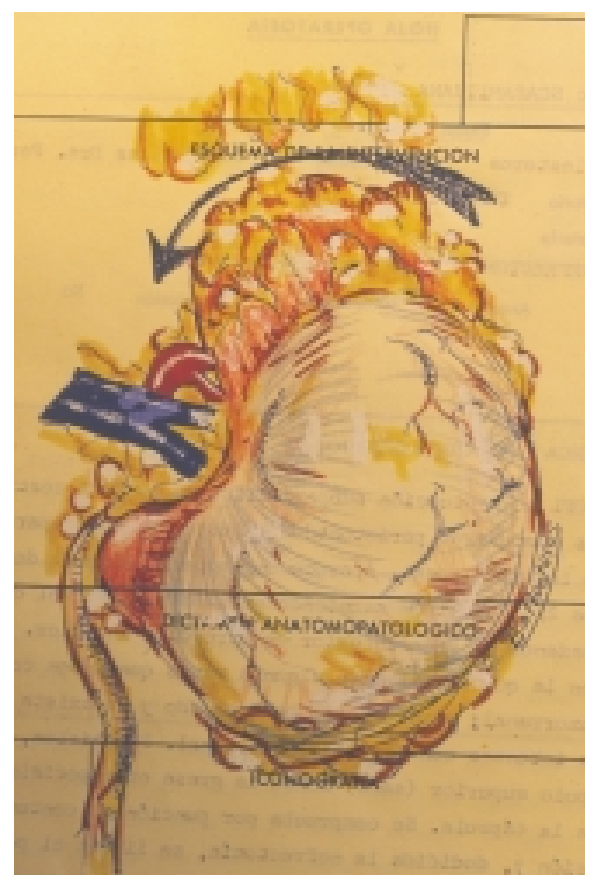

FIGURA 8. Idem. Idem. de la via quirúrgica de abordaje de los vasos renales en un caso de hipernefroma.

los campos operatorios puede ser poco didáctica y suele ser mucho más práctico recurrir al esquema como se evidencia en las imágenes siguientes (Figs. 9 y 10).

Otro "documento clínico" cada vez más importante $\mathrm{y}$, afortunadamente cada vez más implantado, es el Consentimiento Informado en el que se exponen de forma entendible los pormenores, en este caso, quirúrgicos, de los que proponemos como tratamiento. Es un documento básicamente escrito y lo cierto es que muchas veces acompañábamos su lectura de dibujos aclaratorios para que el paciente pudiera entender mejor los pasos de la técnica quirúrgica, dibujos que eran después tirados a

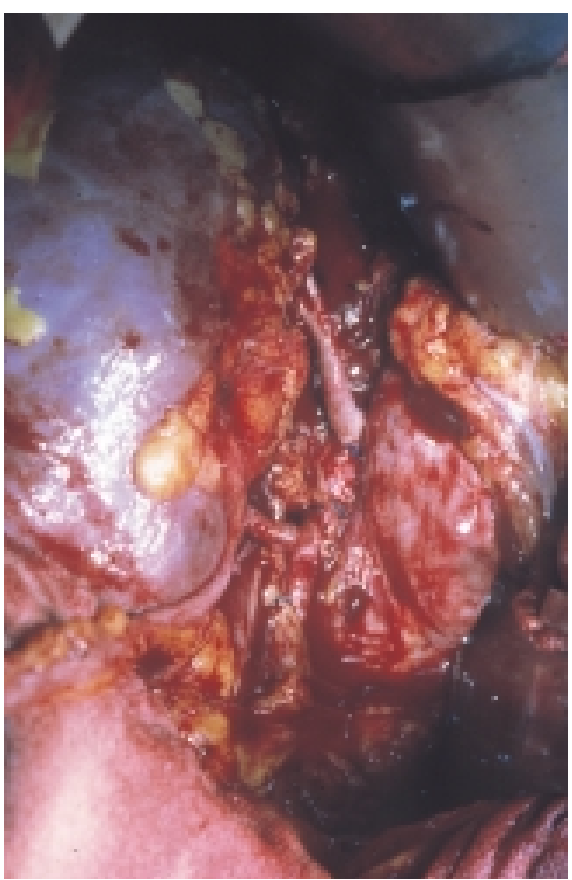

FIGURA 9. Diapositiva de un heterotrasplante renal a comparar con:

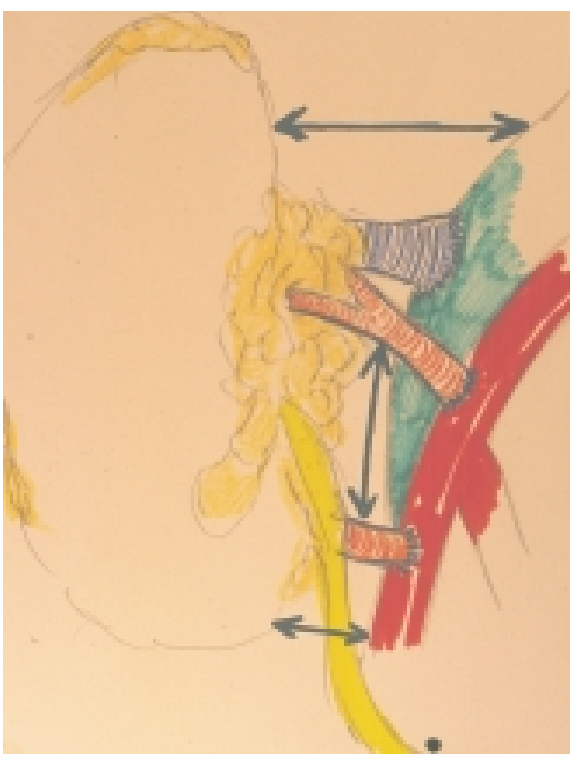

FIGURA 10. Esquema de un trasplante renal. Nótese como se acentúan las distancias entre vasos, de la máxima importancia cara a una reintervención o trasplantectomía.

la papelera. Hablando en una ocasión de estos temas con el Dr. Solé Balcells me comentó que él hacía lo mismo pero que los dibujos quedaban grapados con el consentimiento y eran firmados igualmente por el paciente. Me pareció una excelente idea y le pedí una de esas hojas realizadas espontánea y esquemáticamente para ilustrar este artículo (Fig. 11). 
En el aspecto docente es innegable el valor de la ilustración. De hecho no se concebiría hoy en día una clase, conferencia, mesa redonda, etc., sin el apoyo de las ilustraciones. Bien es cierto que los soportes actuales de tales ilustraciones están cambiando y ya, incluso, la diapositiva está quedando obsoleta pero no obstante eso siempre será necesario un esbozo, bosquejo, esquema que originalmente deba salir de nuestro lápiz frente a un papel aunque, posteriormente, se modifique e incluso transforme a través de la nueva tecnología informática. Grandes docentes han recurrido a la ilustración personal como complemento a sus notas clínicas cuando no han hecho de la ilustración un fin en si mismo de su actividad. Ramón y Cajal ilustraba personalmente sus notas y sus hallazgos sobre el sistema nervioso (Figs. $12 \mathrm{y}$ 13) y aún hoy pueden contemplarse en la antigua Facultad de Medicina de Zaragoza, grandes láminas coloreadas al pastel del propio Don Santiago (y aquí entraríamos en la relación ilustración-investigación).

Resolviendo entre libros antiguos he encontrado el de un autor español, el Dr. Magín Cabanellas, que en 1871 ilustró con su propia mano y litografió un manual de anatomía titulado "Atlas de Anatomía" para estudiantes (Figs. 14 y 15). Quien fue posteriormente cátedro de Medicina Legal de la Facultad de Medicina de Barcelona, Prof. M. Sales Vázquez, participó en la ilustración del libro de "Operatoria Urológica" (Fig. 16) que escribiera Don Manuel Serés, cátedro de Anatomía, en 1925 junto a otro dibujante clásico, no médico, el Sr.

R. Alemany que después colaboró intensamente con Antonio Puigvert que, a su vez, había sido discípulo del Prof. Serés...

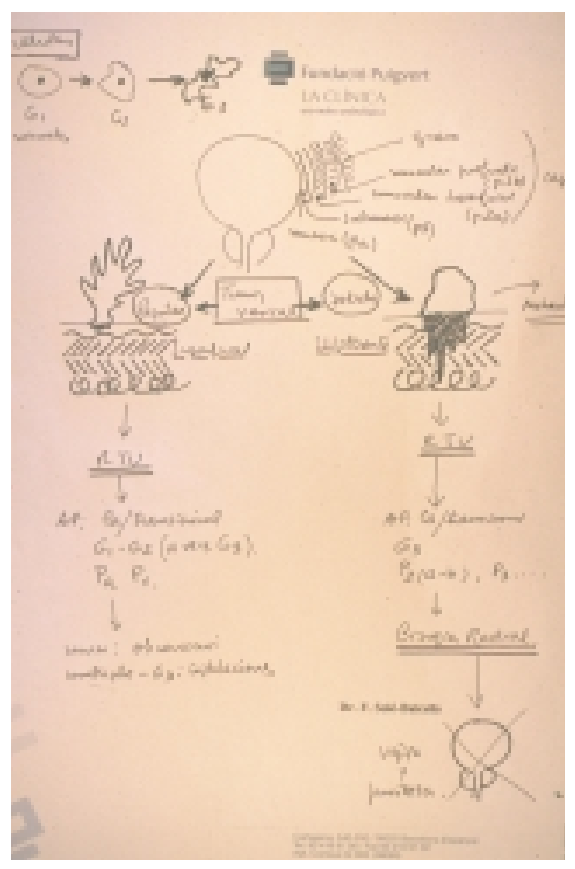

FIGURA 11. Consentimiento informado ilustrado por el Dr. Solé Balcells en un caso de tumor vesical. En él se explican los diversos tipos de tumor y la necesidad, en su caso, de la cistectomia (gentileza del autor).

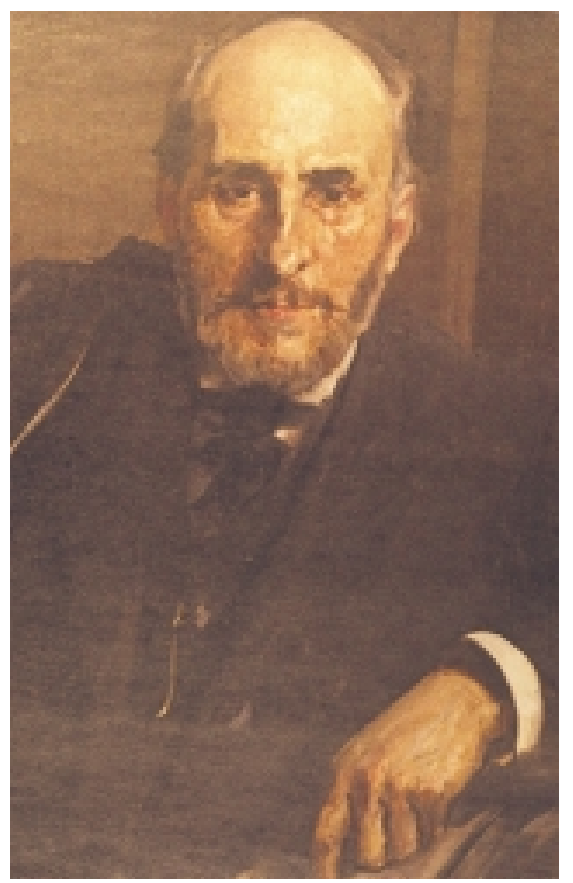

FIGURA 12. Don Santiago Ramón y Cajal, por J. Sorolla. 


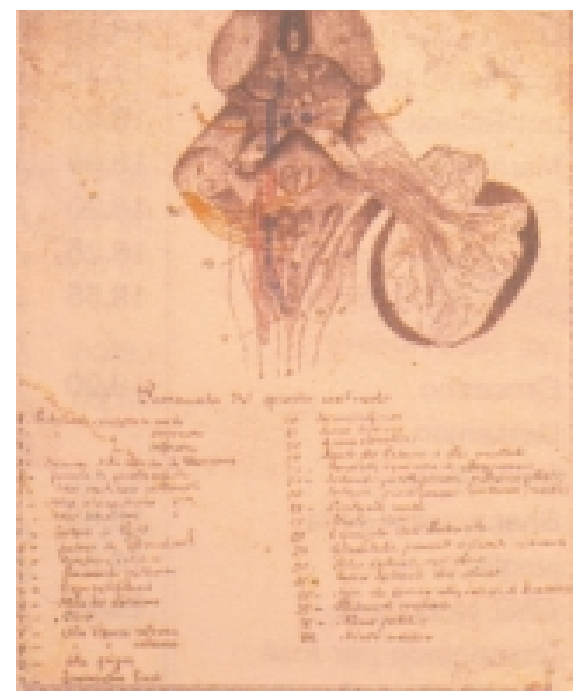

FIGURA 13. Esquemas de los apuntes de Don Santiago.

$Y$ que no decir de aquel estudiante de La Sorbona, en París, que ya destacara en los dibujos que hacía sobre sus apuntes de Medicina y que, ya médico, en Nueva York dio un impulso decisivo a la simbiosis de sus aficiones: la fisiología y la pintura. ¿Quién no ha admirado los óleos de Frank Netter sobre la anatomofisiología del cuerpo humano? "Sólo" 2.300 dibujos fueron realizados durante 25 años, trasmitiendo no sólo elementos de la anatomía estática sino estados de la fisiopatología que caracterizaban en la mente de sus lectores la esencia de la enfermedad (Fig. 17).

Recientemente he adquirido el libro "Functional Reconstruction of the Urinary Tract and GynaecoUrology" de Richard Turner-Warwick, hombre que se reconocía afortunado por haberse podido dedicar con casi exclusividad a la cirugía que le gustaba que era la uretra y el suelo pelviano. Me llamó poderosamente la atención que en dicho tratado dedicara un capítulo a: "The art of medical

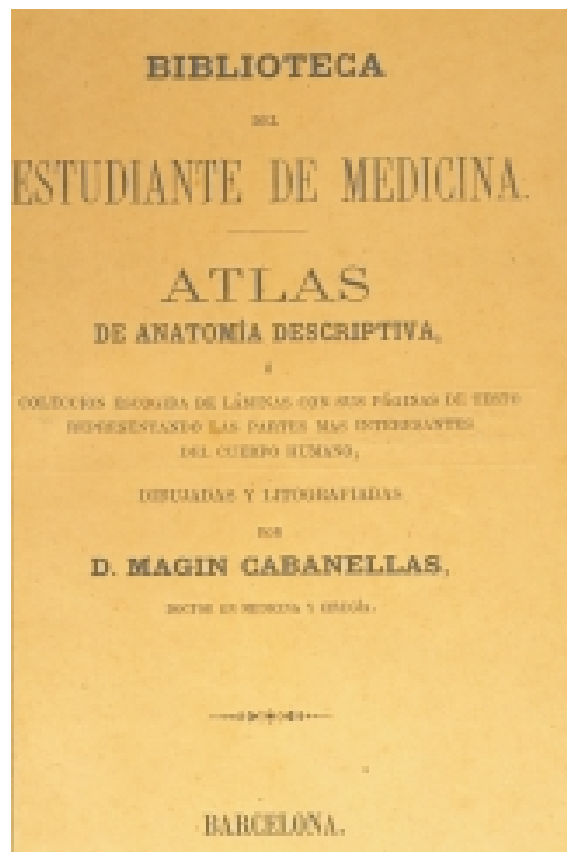

FIGURA 14. Portada del "Atlas de Anatomia" de Don Magin Cabanellas con dibujos y litografias originales del autor (1871).

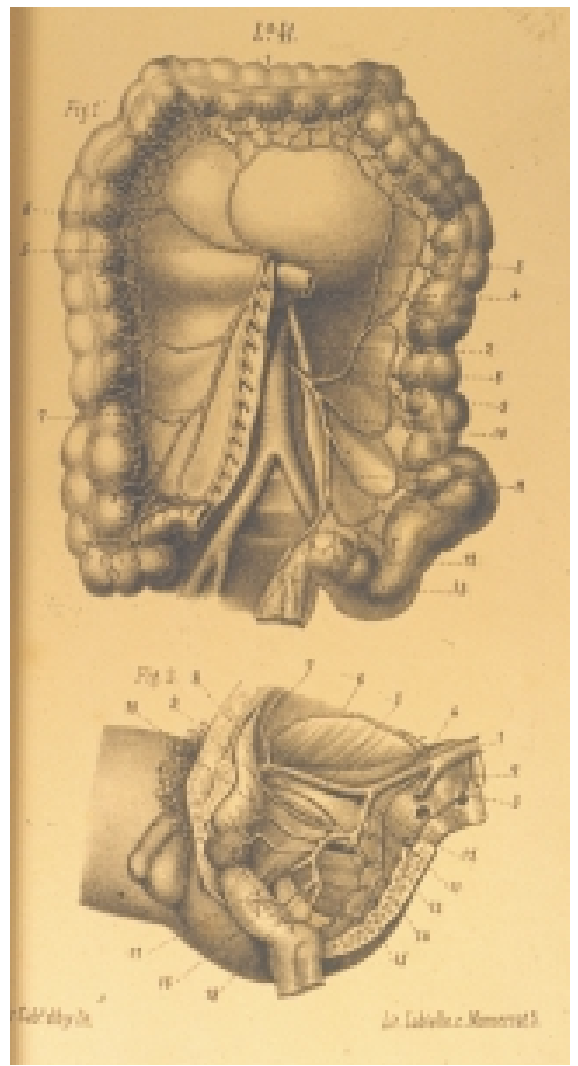

FIGURA 15. Un ejemplo de las litografias de Don Magin. 
ED ITO RUAL

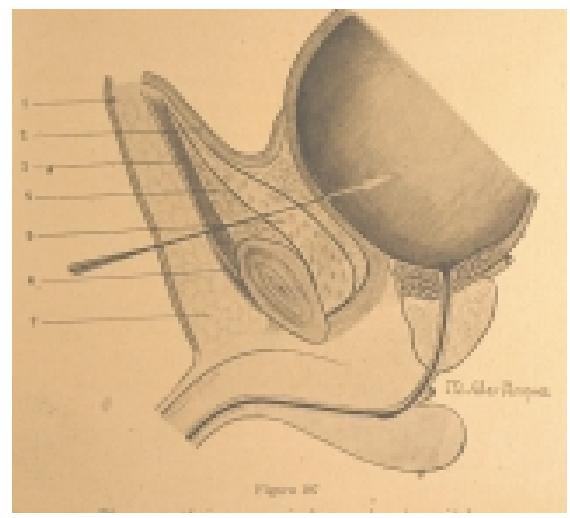

FIGURA 16. Dibujo del Prof. Sales Vázquez para Operatoria Urológica del Prof. Manuel Serés (1925).

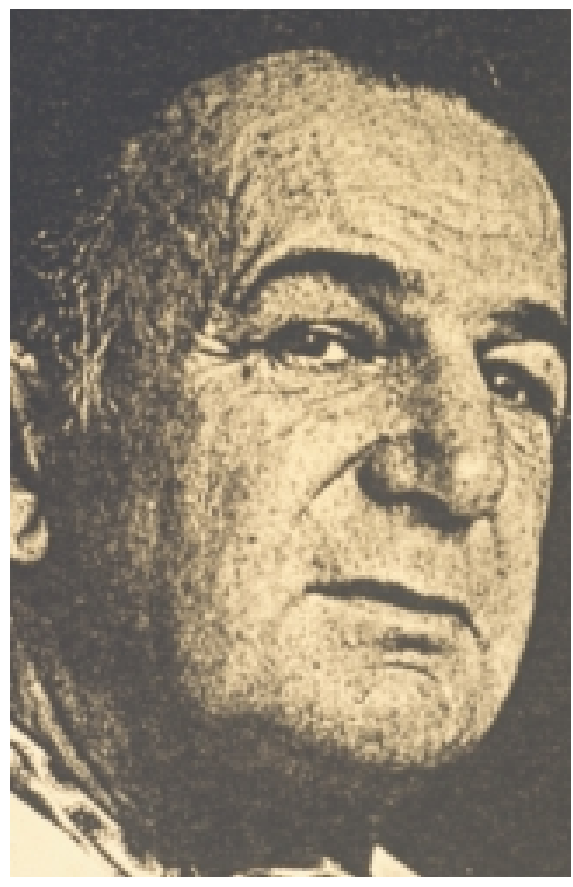

FIGURA 17. Frank Netter.

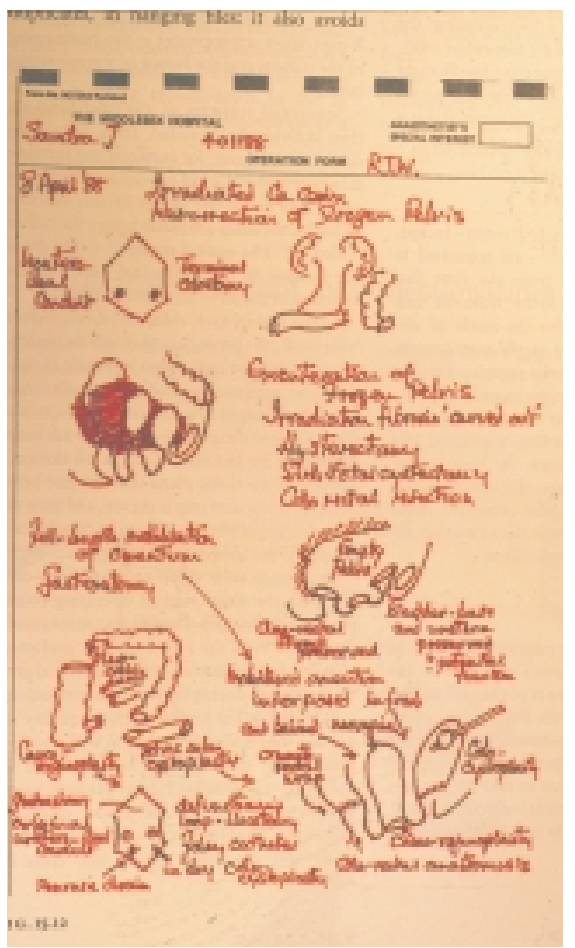

FIGURA 18. Esquemas operatorios de $R$. Turner Warwick (de Functional Reconstruction of Urinary Tract and Gynaeco-Urology).

illustration", dando un merecido reconocimiento a las personas que sobre la base de sus propios esquemas (Fig. 18) realizaban las láminas definitivas que ilustraban sus artículos o libros, como significación clara de que sin ese apoyo sería muy difícil impregnar un texto de las pretendidas enseñanzas. Como creo que es justo hacer relación de los colaboradores, no médicos, en las tareas de ilustración quisiera mencionar, de nuevo, a los Sres. R. Alemany, Antonio Belenguer y Pere Lluís León que representan tres épocas sucesivas en la ilustración médica en nuestra ciudad, los dos últimos mejor conocidos por haber colaborado conmigo en diversas ocasiones (Figs. 19 y 20).

No fue médico pero no podríamos olvidar a un personaje que encarnó el espíritu renacentista en muchísimas facetas de la vida entre ellas la pintura y el estudio anatómico del cuerpo humano. El gran Leonardo (Fig. 21) fue filósofo, sentando las bases de definición moderna del método científico adelantándose al propio Descartes; fue físico anticipando el principio de la inercia; fue astrónomo, geólogo, biólogo, matemático e ingeniero. Descubrió la circulación constante de la sangre, estudió el 


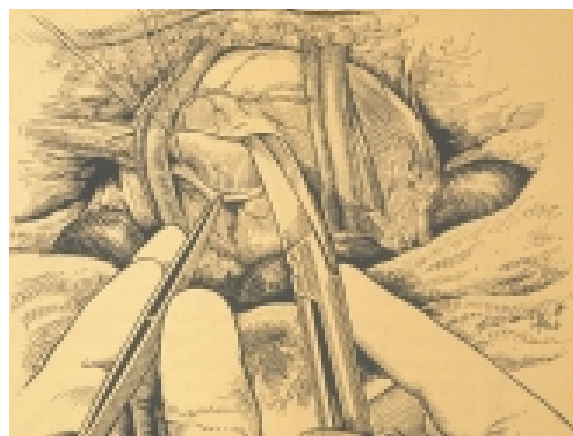

FIGURA 19. Dibujo a plumilla de la cirugia de la Hidronefrosis por Antonio Belenguer en Tratado de Operatoria Urológica de A. Puigvert (1971).

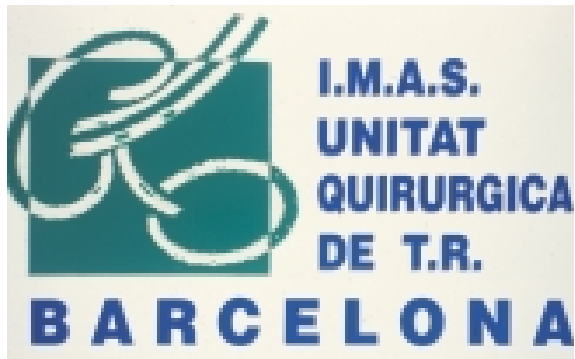

FIGURA 20. Logotipo de Pere Ll. León para nuestra Unidad de Trasplante Renal.

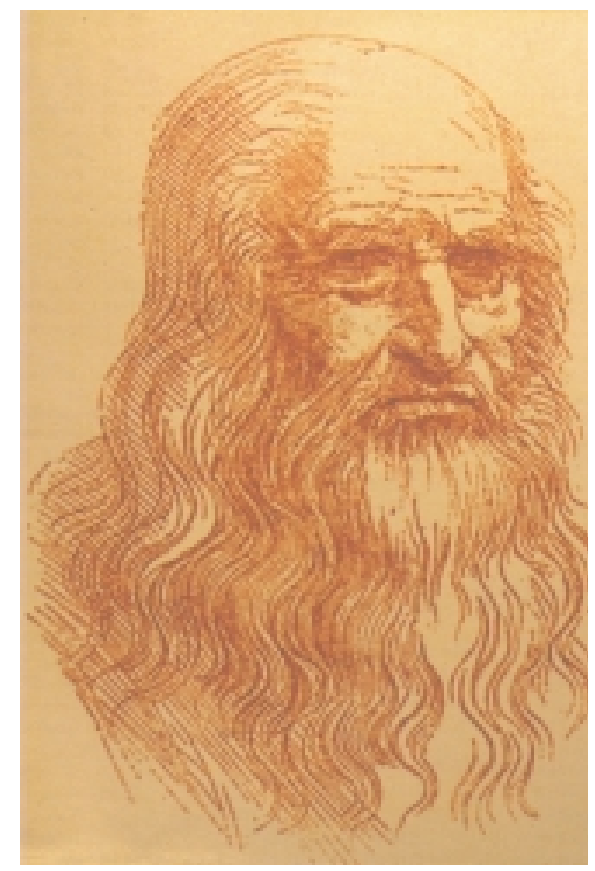

FIGURA 21. Autoretrato (sanguina) de Leonardo da Vinci.

corazón y el órgano de la vista y se le atribuyen proyectos de helicóptero, excavadoras, relojes, higróme-

tros, ingeniería militar, etc. Menos conocidos son sus conocimientos sobre venenos y ponzoñas al haber desempeñado el cargo de maestro de banquetes en la corte de los Sforza. En 1504 inició sus disecciones en cadáveres con bellísimos ejemplos de dibujos anatómicos (Fig. 22) que ilustraron, en 1910, su proyecto para "Il libro dell' Anatomia" que nunca llegó a publicar ya que sus estudios en el Hospital del Espíritu Santo, en Roma, fueron interrumpidos por "prácticas sacrílegas" por el papa León $\mathrm{X}$. Vivió sus últimos años en el castillo de Cloux donde realizó diversos proyectos de urbanismo para su gran admirador, Francisco I, quien le asistió en los últimos instantes de su vida como queda reflejado en un conocido cuadro de Ingres expuesto en el Petit Palais de París y que, en estos días, hemos visto expuesto en la Pedrera de nuestra ciudad.

La actual y progresiva futura implantación de la metodología informática nos llevará a la informatización de la Historia Clínica y a otros documentos en los que podremos "pegar" imágenes radiológicas o de otro tipo, lo que parece que pudiera relegar la elaboración artesanal propia a favor de la "imagen real". Siendo en parte cierto, yo pienso que las reflexiones personales en el aspecto iconográfico siempre tendrán cabida y muy especialmente todo lo que haga referencia a las técnicas quirúrgicas... No dispondremos de "originales" en la historia informatizada pero habremos tenido que partir de uno de ellos para, tras scanearlo, pegarlo al documento... aunque las posibilidades de la expresión artística "directa" en un ordenador parecen no tener límite hoy en día... 


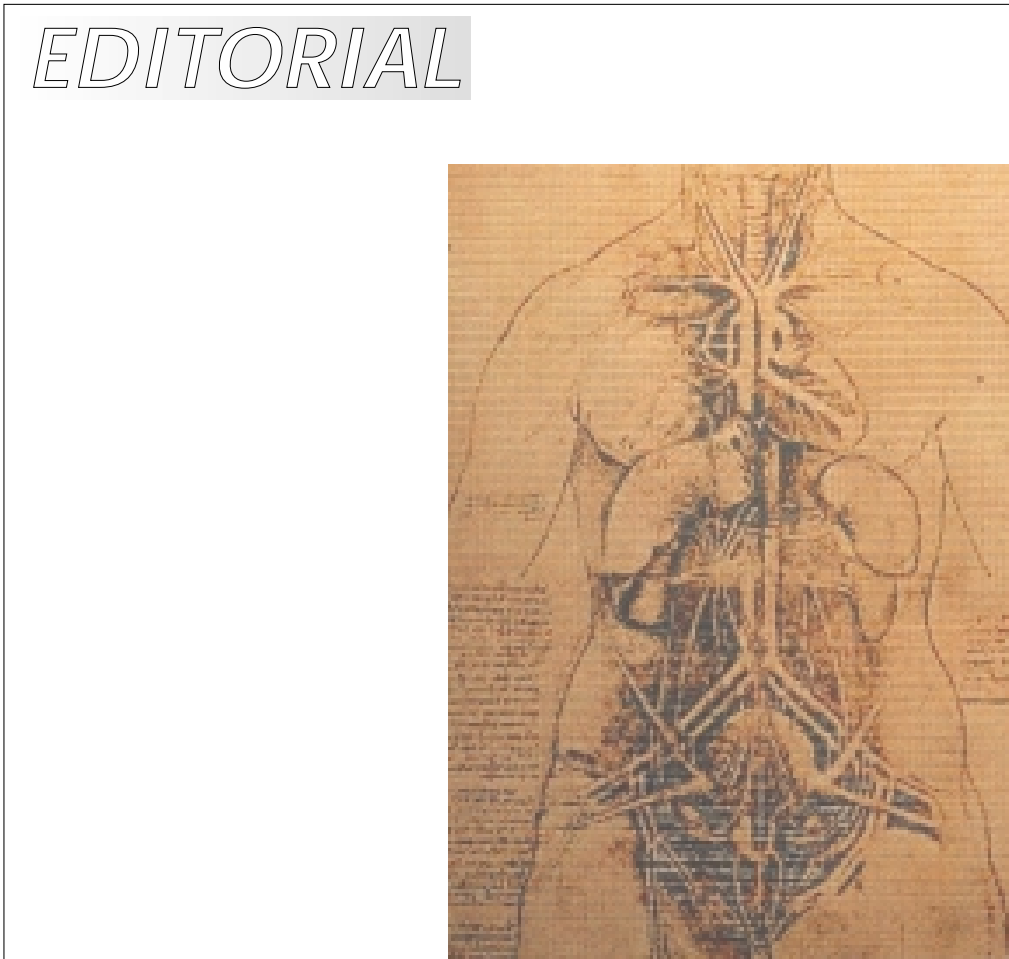

FIGURA 22. Dibujo anatómico de Leonardo tras disección del cuerpo femenino (1510). Royal Library. Castillo de Windsor. UK.
Lo dicho hasta ahora solo pretende exponer y resaltar la ilustración como ayuda en nuestra actividad con connotaciones que pueden alcanzar a nuestra responsabilidad legal frente a reclamaciones profesionales. Recordemos como todos los expertos recomiendan recurrir a todos los mecanismos necesarios (subrrayados, llamadas de atención, utilización de colores, dibujos, etc.) en nuestra documentación que sirvan para demostrar la importancia que hemos dado, en nuestras historias clínicas, a hechos relevantes referidos por los pacientes. Pensemos que la actual documentación clínica de una alta hospitalaria puede llegar a reunir hasta 22 documentos diferentes desde los datos administrativos a los consentimientos informados; si en ellos somos capaces de recurrir, mediante ilustraciones, a la mejor comprensión del ingreso y estancia del paciente no sólo contribuiremos al mejor entendimiento de toda nuestra actuación sino que afianzaremos la primera línea de defensa ante acontecimientos legales adversos.

La pretendida dificultad que a veces se esgrime en la realización de tales ilustraciones debería ser un acicate para superarla. A Chillida se le atribuye la anécdota de obligarse a dibujar con la mano izquierda porque era diestro y el trabajo que no le ofreciera una dificultad añadida carecía de interés para él.

No quiero finalizar sin pedir excusas por no haber reflejado, probablemente, a facultativos y quizá urólogos que hayan destacado en estos aspectos ilustrativos y de los que desconozco tales habilidades. La pretensión del editorial es realzar el "método" aunque no puede uno sustraerse de referir los ejemplos que por ser próximos son mejor conocidos y obligan a las referencias personales. 